\title{
A normatização disciplinar da historiografia universitária: Francisco Iglésias e a sua tese de Livre- Docência* $^{*}$
}

\author{
The disciplinary norming of the university historiography: Francisco \\ Iglésias and his Academic Thesis
}

\author{
Alessandra Soares Santos \\ alessandrast@ufmg.br \\ Professora efetiva \\ Universidade Federal de Minas Gerais \\ Rua Tenente Garro, 627, ap. 301 - Santa Efigênia \\ 30240-360 - Belo Horizonte - Minas Gerais \\ Brasil
}

\section{Resumo}

A redefinição dos códigos disciplinares da pesquisa histórica pelos primeiros historiadores oriundos das universidades brasileiras não ocorreu por meio de nenhuma revolução ou mudança rápida de paradigma. Assim, os indícios da construção de novas maneiras de fazer e pensar a história devem ser localizados na forma como se concebeu cada empreendimento de escrita específico. Analisamos neste artigo o potencial discursivo e a recepção da tese de livre-docência de Francisco Iglésias e de seus primeiros textos publicados a partir de sua efetivação como docente, na década de 1950, para afirmar e produzir uma reorganização disciplinar do conhecimento histórico produzido na universidade. Consideramos que a vinculação institucional de seu texto não foi um procedimento puramente formal: foi a partir da universidade que ele justificou sua escolha temática e diferenciou sua escrita de outras produções historiográficas.

\section{Palavras-chave}

Historiografia brasileira; Conhecimento histórico; Francisco Iglésias.

\section{Abstract}

A disciplinary code of a history research was redefined by the first historians graduated in Brazilians universities. But it didn't happen like a revolution or a radical paradigm change. Thus, the new ways to make history e think about the discipline must be connected with the different ways to write a history text. That paper aims to analyze the Francisco Iglésias thoughts about history knowledge, the discursive potential and the reception of his academic thesis, as well as his first papers published in the 1950 's, to confirm and produce a disciplinary reorganization made by professional historians, in the universities. We consider that the institutional bonds manifested on his texts weren't just a formal procedure, but a deliberated way to distinguish from others history texts produced in that time.

\section{Keywords}

Brazilian historiography; Historical knowledge; Francisco Iglésias.

Recebido em: 21/10/2016

Aprovado em: 9/3/2017

*Pesquisa financiada pela CAPES. 
A identidade da história e do historiador, que, no Brasil, desde o século XIX eram privilegiadamente constituídas no interior dos institutos históricos e geográficos, ganhou um novo lugar de gestação a partir das décadas de 1930 e 1940 com a ampliação do ensino superior e a institucionalização dos cursos de História. A essa mudança, contudo, não correspondeu de imediato uma alteração substancial nas técnicas, nos métodos de investigação e no levantamento de novas questões e hipóteses sobre o passado, pois a condução do conhecimento histórico para dentro da universidade brasileira resultou na assimilação de técnicas da ciência histórica que foram desenvolvidas fora dela.

Não se trata, portanto, de perguntarmos qual o impacto da institucionalização universitária do saber histórico sobre a historiografia brasileira, nem de questionarmos até que ponto esta reorganização social rompeu com uma tradição historiográfica e impôs outra; afinal, não estamos diante de nenhum evento fundador. As transformações internas e externas ao discurso histórico não atendem aos mitos de uma constituição progressiva da historiografia, configurado por suas relações com o sistema no qual é elaborado e em contextos específicos. Partimos do pressuposto de Certeau (2008) de que toda pesquisa se articula com um lugar de produção socioeconômico, político e cultural, com uma "instituição do saber" que condiciona uma linguagem científica. Daí emerge o seu valor documental e a contribuição das obras históricas do passado para o conhecimento da própria história.

Por outro lado, é preciso considerar também que houve uma importante reconfiguração da função social do historiador a partir de sua inclusão no universo do ensino superior e da construção da ideia da "universidade moderna", o que impôs a transformação da maneira como os historiadores justificavam o seu próprio trabalho diante daqueles que não possuíam uma formação específica. Assim, não se pode dizer que as circunstâncias sociais que permitiram a emergência desse novo lugar de produção da historiografia não estivessem em estreita relação com uma modificação discursiva dos parâmetros disciplinares do saber histórico. Os indícios desta redefinição podem ser localizados na forma como se concebe cada empreendimento de escrita específico, já que é a partir da identificação das normas que traduzem as exigências disciplinares em determinados contextos - os objetos históricos considerados legítimos, a estruturação do texto, a afirmação de conceitos, as citações, os diálogos teóricos - que podemos perceber as mudanças efetuadas no conhecimento a partir dos impulsos de um novo lugar de produção da história, bem como a permanência de ideias e práticas alheias à afirmação do modelo.

Embora essa disciplinarização esteja desvinculada de qualquer proposição autoral, suas regras são constantemente reatualizadas por uma corporação discursiva de sujeitos específicos que garantem o advento e a manutenção de seus princípios através das escolhas concretas que realizam. Ao mesmo tempo em que obedece a regras próprias, a disciplina se articula aos enunciados individuais que escapam do anonimato e arrogam para si a função de preservá-la (FOUCAULT 2003). Acreditamos que o historiador Francisco Iglésias (1923-1999) foi um destes agentes que contribuíram para dar uma 
feição própria à historiografia produzida na universidade, pois, para participar de seu ordenamento discursivo, ele não só satisfez todas as exigências para ter acesso a certo número de regras do ofício, como parece ter se qualificado para atualizá-las.

Formado na segunda turma do curso de Geografia e História da Universidade de Minas Gerais em 1945, Francisco Iglésias ingressou como professor da Faculdade de Ciências Econômicas em 1949 e defendeu sua tese de livre docência em 1955. Autor de inúmeros livros, artigos, prefácios, comentários e relatórios técnicos; participante de incontáveis bancas de concursos públicos, defesas de teses e monografias e membro de conselhos editoriais de revistas acadêmicas, ele não só se submeteu como participou da construção dos critérios disciplinares da historiografia universitárias desde a sua institucionalização.

Analisamos aqui o potencial discursivo da tese de livre-docência de Francisco Iglésias e de seus primeiros textos publicados a partir de sua efetivação como docente, na década de 1950, para afirmar e produzir uma reorganização disciplinar do conhecimento histórico produzido na universidade. A partir da recuperação dessas reflexões identificamos uma postura teórica estreitamente relacionada ao anseio por uma metodologia histórica própria ao empreendimento científico universitário.

\section{Incorporando uma codificação}

Ao ingressar como professor na Faculdade de Ciências Econômicas da UFMG, Francisco Iglésias incorporou uma codificação que, para além de representar sua inserção na prática formal do discurso acadêmico, alterou o próprio conteúdo daquilo que estava sendo dito. Tal movimento pode ser percebido pela análise da tese de livre-docência apresentada por ele em 1955 e publicada em 1958 como Política econômica do governo provincial mineiro (1835-1889), e do livro Introdução à historiografia econômica, publicado em 1959 - suas primeiras realizações historiográficas a partir da universidade.

Francisco Iglésias começou a escrever sua tese de livre-docência em 1953, motivado pela vontade de permanecer como professor da Faculdade de Ciências Econômicas. ${ }^{1}$ Ele ocupava o cargo de assistente de ensino desde 1949, mas, de acordo com o Regulamento da Assistência de Ensino, aprovado em 1951, ele só poderia permanecer na função por até quatro anos. ${ }^{2}$ Após esse período, o assistente deveria se submeter ao concurso de livre-docência, passando a professor adjunto. ${ }^{3}$ O concurso foi realizado em 1955, tendo como comissão julgadora os professores Alice Piffer Canabrava, Emílio Guimarães Moura, Hélio

\footnotetext{
${ }^{1}$ Embora Francisco Iglésias tenha iniciado sua carreira na Faculdade de Ciências Econômicas da UFMG lecionando Geografia Econômica, logo foi convidado pelo catedrático de História Econômica, Rodolfo de Abreu Bhering, para assisti-lo nesta cadeira.

${ }^{2}$ Como assistente de ensino, Francisco Iglésias lecionou as disciplinas Geografia Histórica, Geografia Econômica e História do Brasil para o curso preparatório de candidatos ao concurso de habilitação da Faculdade de Ciências Econômicas, também chamado de curso pré-vestibular ou curso anexo, entre 1951 e 1954 . De 1956 até 1958, já concursado, ele lecionou para os cursos de Política e Sociologia e de Administração Pública as disciplinas História da Economia, História Social e Política do Brasil e História Econômica Geral e do Brasil.

${ }^{3}$ Regulamento da Assistência de Ensino aprovado pela Congregação da Faculdade de Ciências Econômicas em 16 de março de 1951.
} 
Viana, Raul Jobim Bittencourt e Rodolfo de Abreu Bhering. Sua tese foi publicada pelo Instituto Nacional do Livro em 1958 e é esta a edição que usamos aqui.

Embora já tivesse publicado inúmeros artigos e resenhas em revistas acadêmicas, a tese de livre-docência pode ser considerada a obra de estreia de Francisco Iglésias na universidade. Em termos de esforço investigativo e tempo despendido, ele fez desse trabalho inaugural um produto exemplar do lugar de produção científica que a universidade representava. De acordo com sua explicação inicial, o que o teria levado ao assunto da política econômica da província mineira seria "a preocupação com a realidade de Minas e o nosso conceito de tese e de trabalho universitário", visto que, na sua concepção, para realizar um estudo desse tipo, o historiador precisaria ter consciência dos limites impostos pela pesquisa científica, escolhendo temas cuja documentação pudesse ser encontrada com relativa facilidade (IGLÉSIAS 1958, p. 9-11).

A vinculação institucional de seu texto, portanto, não foi um procedimento puramente formal: foi a partir da universidade que ele justificou sua escolha temática e diferenciou sua escrita de outras produções historiográficas. Daí ele ter inaugurado em seu primeiro empreendimento acadêmico uma prática que se tornou comum em suas obras: o exercício de autolocalização da sua contribuição intelectual. A recorrência desta maneira de apresentar seus trabalhos revelava a sobrevivência de uma preocupação com a legitimação da produção da historiografia universitária confiada no cumprimento dos objetivos da própria universidade. Tal esforço tinha a pretensão de definir a realização de seus estudos em função da relação que eles mantinham com outros trabalhos e com as problemáticas exploradas pelo grupo de pesquisadores da comunidade científica.

A convicção de Francisco Iglésias de que a historiografia universitária deveria contribuir para a ampliação do conhecimento oferecendo um ponto de vista original sobre determinado assunto levou-o ao século XIX, pois ele constatou que "a vida provincial mineira quase ainda não existe como tema para o historiador. À vista de tal verificação, animou-nos a ideia de que qualquer esforço teria sentido" (IGLÉSIAS 1958, p. 11). A ausência de bibliografia para a fase provincialfaria todo e qualquer empreendimento ser inédito, realizando de forma mais estreita o propósito suposto da universidade, que era "contribuir mais efetivamente para o conhecimento do país" (IGLÉSIAS 1958, p. 14). De acordo com Iglésias, este objetivo deveria ser traduzido não somente pela divulgação do que já era conhecido, mas, sobretudo, pelo esforço de produzir conhecimento original. Sua avaliação era a de que "em países como o nosso, mais talvez que em outros, esse é um dever, pois há ignorância generalizada das suas coisas, enquanto o esforço intelectual, por falta de tradição ou apoio, ainda é apenas teimosia de obstinados" (IGLÉSIAS 1958, p. 14-15).

A escrita de Francisco Iglésias elaborada até então, cujos textos preencheram as páginas de jornais e revistas, estava restrita ao cumprimento daquela primeira tarefa. Embora ele tenha valorizado a história de Minas Gerais por meio da publicação de resenhas de obras de viajantes que passaram pelo estado, como John Mawe, e de historiadores, como Diogo de Vasconcelos, sua contribuição ainda não tinha ido além dos limites da difusão do conhecimento existente. $E$ 
esse conhecimento, segundo sua observação em um artigo publicado em 1949, era extremamente insatisfatório, pois não ultrapassava a fase do arrolamento de nomes e datas, e que "a história mineira tem sido mais uma crônica do que história propriamente":

O estudo das coisas mineiras bem poucas vezes se tem chegado à História [...]. Para que haja história, como diz o lugar comum, é preciso que haja interpretação. No mais, temos apenas grossos relatórios que ainda não foram trabalhados pelo espírito crítico característico do historiador: temos a matéria bruta com a qual se faz a história, mas não a história propriamente. $O$ estudioso que não dá um passo além dessa primeira fase não merece ser chamado historiador; cabem-lhe melhor outros epítetos (IGLÉSIAS 1949, p. 1).

Quando Francisco Iglésias escolheu o tema de sua tese, preocupava-o cumprir as exigências de um trabalho universitário sob o ponto de vista da viabilidade científica e da originalidade, daí ter escolhido um tema próximo Minas Gerais - e pouco examinado - a vida provincial. Como postulante de cargo no ensino superior, sua tese guardou as marcas deste "rito iniciático" na abundância de notas e na presença de bibliografia crítica. Às notas de referência foram juntadas outras, mais esparsas, para discutir os trabalhos de outros historiadores, norma que se estendeu ao conjunto da produção histórica universitária. ${ }^{4}$ De fato, segundo Grafton, a história das notas de rodapé pode mostrar as mutações que a narrativa histórica sofreu ao longo dos séculos em decorrência das lutas por poder institucional (GRAFTON 1998, p. 189). Mas, como a presença delas não é suficiente para garantir a cientificidade do texto, daí decorre a necessidade de dar significado a outras demarcações que podem ajudar a esclarecer os postulados epistemológicos da historiografia universitária.

De acordo com Delacroix, Dosse e Garcia (2012, p. 91), o novo modo de escrever história imposto à universidade afetou o estilo dos historiadores, "que são convidados a romper com a retórica e dar a seus trabalhos [...] o tom desenvolto e austero da ciência" Nesse sentido, Francisco Iglésias organizou seu espaço textual de acordo com a organização do espaço social no seu entorno. Como observou Certeau, a historiografia produz sua credibilidade através da linguagem referencial que tem por função comprovar o discurso: as citações e notas produzem um "efeito de real" e remetem a um "lugar de autoridade". A aparente comprovação de seus enunciados, portanto, se baseia no ato da palavra como ato de autoridade. Para além dos dispositivos de produção de credibilidade, a linguagem referencial da historiografia ajuda a demarcar o espaço no qual sua "encenação escriturária" ganha sentido, pois "citando, o discurso transforma o citado em fonte de credibilidade e léxico de um saber" (CERTEAU 2008, p. 102). A relação entre o lugar deste saber e sua exterioridade se faz presente na própria interpretação que é oferecida ao leitor: 
[...] o discurso produz um contrato enunciativo entre o remetente e o destinatário. Funciona como discurso didático, e o faz tanto melhor na medida em que dissimule o lugar de onde fala (ele suprime o eu do autor), ou se apresente sob a forma de uma linguagem referencial (é o "real" que Ihes fala), ou conte mais do que raciocine (não se discute um relato) e na medida em que tome os seus leitores lá onde estão (ele fala sua língua, ainda que de outra maneira e melhor do que eles) [...] Este discurso não deixa escapatória. A estrutura interna do discurso trapaceia. Produz um tipo de leitor: um destinatário citado, identificado e doutrinado pelo próprio fato de estar colocado na situação da crônica diante de um saber (CERTEAU 2008, p. 102-103).

Mas, ao precisar alguns aspectos de sua construção historiográfica sua motivação, suas escolhas conceituais e temáticas -, Francisco Iglésias confrontou a imposição do discurso histórico de se situar fora da experiência que Ihe confere crédito. Ele mostrou que sua escrita histórica estava controlada pelas práticas das quais era resultado, sendo ela própria uma prática social vinculada a uma instituição supostamente mais legítima. Antes de fixar como início da sua narrativa aquilo que, na realidade, era um ponto de chegada da pesquisa histórica - um dos aspectos que caracterizam a passagem da prática investigadora à escrita e que Certeau chamou de "inversão escriturária" -, Iglésias conduziu seu leitor ao lugar de onde falava.

A institucionalização universitária do conhecimento histórico estava provocando nos agentes que dela participavam uma tentativa de reconstrução da identidade disciplinar da história, do historiador e de sua legitimidade científica, daí a pertinência dessa estratégia. Ainda que Iglésias tenha manifestado o reconhecimento do valor das contribuições que foram dadas por vários autores mineiros, ele não reconheceu a cientificidade nos empreendimentos historiográficos anteriores, acusando-os de reforçarem mitos e fantasias ao invés de esclarecerem a realidade; mais que isso, foi em oposição a este modelo que procurou afirmar o horizonte científico da sua tese. Seu papel deveria ser "colocar o assunto no domínio da pesquisa e das noções objetivas, pondo de lado o saudosismo romântico e ingênuo" (IGLÉSIAS 1958, p. 10). A crítica ao "amadorismo" das produções históricas sobre Minas Gerais já tinha aparecido em um artigo de 1952, no qual afirmava que:

A história de Minas, para nós pouco mais tem sido que lembrança orgulhosa acompanhada de suspiros. Se esse estado de espírito pode ser compreensível em pessoas que perderam o que tinham e vivem em cidades mais antigas, entre restos de um passado superior ao presente é de todo injustificável fora dos quadros de uma lamentação aborrecida que resulta de uma condição mórbida que não tem sequer o encanto de certas correntes de pensamento tradicionalista romântico (IGLÉSIAS 1952).

Com a expectativa de uma mudança evolutiva, Francisco Iglésias classificou o conhecimento histórico sobre Minas Gerais como em "estado rudimentar" e atribuiu esta condição a dois fatores: a falta de formação da maioria dos estudiosos e a prudência excessiva que os impediria de avançar nas interpretações (IGLÉSIAS 1949, p. 1). Daí ele ter esclarecido em sua tese 
que buscou compreender a realidade de Minas Gerais no século XIX com as ferramentas que este novo lugar de produção de conhecimento - a universidade - poderia oferecer, ou seja, "com a objetivação de problemas fundamentais e com a adoção de métodos e técnicas adequados" (IGLÉSIAS 1958, p. 9). O que postulava, portanto, era a adoção de uma nova atitude cognitiva, uma ruptura epistêmica com o que ele considerava fazer parte do senso comum e da ideologia graças à produção de uma história problematizadora em lugar da simples reprodução de fatos cuja existência era supostamente irredutível.

Se as possibilidades da escrita da história nestes termos estavam sendo reivindicadas, como é sabido, por outros historiadores desde a década de 1930, vale ressaltar que Francisco Iglésias contribuiu para a articulação desta história "nova" ao meio universitário brasileiro como condição indispensável para a sua realização. Antes dos anos 1960 e 1970, quando emergiram os primeiros cursos de pós-graduação em História, já havia um esforço para deslocar a produção historiográfica dos lugares institucionais considerados tradicionais ou aristocráticos (IHGB, ABL, ISEB e etc.) para a universidade, que, pelo menos no contexto mineiro, já dava oportunidade para que discentes e docentes sem vínculos com as elites tradicionais nela ingressassem, como era o caso do próprio Iglésias.

A inspiração historiográfica declarada de Francisco Iglésias foi a obra do economista e historiador sueco Eli F. Heckscher sobre a época mercantilista, o qual se deteve nos planejamentos políticos que influíram no desenvolvimento econômico e não no próprio desenvolvimento econômico (HECKSCHER 1943). Daí Iglésias ter também recortado seu objeto para esclarecer a política econômica, e não os fenômenos econômicos. A consciência de que a análise da política econômica realizada durante todo o Império seria inviável nos limites de uma tese o levou a delimitar cronologicamente seu trabalho entre 1835 e 1889, da Reforma da Constituição à Proclamação da República. No caso do marco inicial, porque foi a partir de 1835 que as províncias passaram a dispor de um governo, de um legislativo próprio e de uma relativa autonomia; quanto ao final, embora tenha reconhecido que os limites adotados seriam antes políticos que econômicos, argumentou que a data teria muito sentido econômico, uma vez que deu início a uma nova estrutura do país, com a substituição do trabalho escravo pelo trabalho livre.

A lógica da ordem temporal presente em sua tese poderia ser classificada, de acordo com o esquema de Norma Côrtes para a geração nacionalista da década de 1950, como uma razão dual: a realidade nacional encerraria uma simultaneidade de diversas fases históricas. Essa noção de "contemporaneidade do não coetâneo", tributária de Ortega y Gasset, rejeita a temporalidade linear e postula a sincronicidade, de forma que "novo e velho, moderno e atraso, atual e inatual, esperanças (projetos de futuro) e ultrapassados (memória e tradição) sempre coexistem em um mesmo momento presente" (CÔRTES 2008, p. 239). Francisco Iglésias percebeu essa temporalidade múltipla, conflitiva e ambígua quando afirmou que: 
[...] entre nós qualquer alteração pequena exige muitos anos: o desenvolvimento não se faz com harmonia - enquanto em certos pontos a estrutura se altera, torna-se complexa ou rica com elementos novos, em outros a estática é a única lei, de modo que vivem agora como viviam no Império, às vezes até com traços mais antigos. Para uma realidade mais profunda, como é a econômica, os fatos políticos quase não contam, as datas não têm sentido. As adaptações são lentas, de modo que mal se percebe que houve mudança de aspecto, tão imperceptível foi a evolução (IGLÉSIAS 1958, p. 13-14).

Pleiteando a cadeira de História Econômica, a tese de Francisco Iglésias se enquadrava nos limites dessa história especial. As histórias especializadas estavam sendo percebidas por ele naquele momento como uma conquista fundamental da "historiografia moderna", na qual ele se esforçava por se autoposicionar. Sua reflexão a esse respeito apareceu no livro Introdução à historiografia econômica, publicado, como visto, em 1959.

Francisco Iglésias rechaçou aí a historiografia romântica do século XVIII e valorizou o esforço de exatidão e ampliação do conteúdo feito no século XIX pela escola metódica. Ele atribuiu a esse momento a diversificação da história, que não deveria ser somente política, mas política, social, religiosa e econômica ao mesmo tempo (IGLÉSIAS 1959). Francisco Iglésias ainda não havia se rendido à crítica dos Annales à história produzida no século XIX e, por isso, ele foi capaz não só de reconhecer o esforço metódico e crítico dos historiadores do XIX, mas também de ressaltar que a história produzida então não era somente política.

A primeira parte de sua tese, intitulada "A realidade política", tratou justamente dos elementos que teriam dado unidade ao Império e que tiveram consequências para a efetivação das políticas por ele implantadas. Somente na segunda parte, intitulada "Política econômica do governo provincial mineiro", é que ele abordou a política econômica propriamente dita. A lavoura, a pecuária, a indústria, a mão de obra, o ensino técnico, o transporte e as finanças foram os elementos que, segundo Francisco Iglésias, caracterizaram a política econômica provincial de Minas Gerais. A cada um deles, o autor dedicou um estudo específico.

\section{A legitimação da historiografia econômica}

Em Introdução à historiografia econômica, ele apresentou uma reflexão teórica que acabou legitimando o esforço em torno da história da política econômica do governo provincial mineiro realizado em sua tese. Os dois textos foram elaborados quase simultaneamente, o que justifica a análise que os toma como complementares. Comparando os temas abordados no livro com os assuntos lançados nos diários de classe das aulas de História da Economia ministradas por ele em 1956 e 1958 para os cursos de Sociologia e Política e de Administração Pública na Faculdade de Ciências Econômicas da UFMG, é possível concluir que esta obra foi resultado das aulas que ele preparava para lecionar a matéria. ${ }^{5}$ Um artigo publicado na Revista da Faculdade de Ciências

\footnotetext{
${ }^{5}$ Diário de Classe e Relação Geral do Ano. Aula de História da Economia do $3^{\circ}$ ano, turma única. Professor
} 
Econômicas, em 1954, também foi aproveitado no livro. Seu interesse não foi discutir a problemática dos processos da vida econômica através dos tempos, mas os problemas metodológicos que explicam "como é que se chegou, entre os historiadores, à colocação do econômico entre suas preocupações, a ponto de desenvolver um ramo especial de seus estudos" (IGLÉSIAS 1959, p. 12).

Depois de situar o leitor no conceito de história econômica e na posição do econômico na historiografia, ele tratou da Escola Histórica de Economia Política desenvolvida na Alemanha durante o século XIX e sua contribuição para a interpretação econômica da história, sobretudo a partir de Karl Marx. Em seguida, estudou a historiografia econômica brasileira, na qual destacou as obras de José Honório Rodrigues, Celso Furtado, Caio Prado Júnior e Roberto Simonsen. Seu livro foi alvo da crítica de Nelson Werneck Sodré, que apontou a ausência de fundamento científico na escolha das fontes pelo autor:

A súmula de Francisco Iglésias sobre historiografia econômica, em que observações pertinentes e acertadas, parece-nos deficiente nas suas fontes. O exame crítico dessas fontes revela um apreço injustificado por algumas a que falta qualquer fundamento científico. No exame das fontes, particularmente quanto crítico, deve antes de tudo, existir uma escala: mais vale selecionar os títulos adequados, definindo as tendências e os métodos a que obedecem, do que proceder a um arrolamento. Em cultura, omitir e esquecer, tem também uma função (SODRÉ 1959, p. 9-11).

A crítica do historiador marxista, autor de uma obra engajada e que foi considerada uma das mais representativas das diretrizes interpretativas do Partido Comunista Brasileiro, era justificada. Em Introdução à historiografia econômica Francisco Iglésias primou pela "sobriedade" com a qual tratou a interpretação econômica da história, sobretudo o pensamento de Karl Marx, sobre o qual percebeu a presença de "forças emocionais" que teriam prejudicado a objetividade da análise: "ele não pode ser criticado sem que o crítico receba o tratamento que se dava aos hereges. Tem que ser visto como perfeito, de valor permanente" (IGLÉSIAS 1959, p. 63). Além de lamentar o fato do pensamento de Marx ter sido bandeira de reivindicações sociais, Iglésias ainda criticou o que classificou como uma modificação do ângulo de análise e do interesse do autor: o uso de suas ideias na luta anti-imperialista e nacionalista, questões que movimentavam os intelectuais da época e que se fazia presente, sobretudo, no ISEB (Instituto Superior de Estudos Brasileiros), o lugar de onde Sodré falava. Dentre as fontes citadas e que poderiam ter motivado as críticas de Sodré estava a obra La vocation actuelle de la sociologie, de Georges Gurvitch. O autor defendia o ideal do cientista neutro e desinteressado e afirmava que o pensamento de Marx tinha sido objeto de deformação ideológica, sobretudo na configuração da equivocada teoria do fator econômico predominante.

Em Introdução à historiografia econômica, Francisco Iglésias pretendeu "evidenciar a modernidade da historiografia econômica" e relacionar seu

Francisco Iglésias. Ano letivo 1956; Diário de Classe e Relação Geral do Ano. Aula de História da Economia do $3^{\circ}$ ano, turma única. Professor Francisco Iglésias. Ano letivo 1958. Arquivo da Memória Institucional da FACE/UFMG. 
surgimento a alteração da ordem social europeia. O aparecimento e o desenvolvimento da historiografia econômica foram ainda compreendidos no contexto mais amplo da ciência social e dos estudos históricos:

Se a sociologia afirma que todos os fenômenos sociais são fenômenos globais, com o desenvolvimento das pesquisas históricas tornou-se evidente a necessidade de especialização. Era impossível a alguém dominar toda a matéria que se compreendia sob os títulos ambiciosos de História Universal, História Geral ou História da Civilização. Impunha-se ao estudioso a especialização em determinado povo, época ou tipo de atividade ou preocupação. Tomando-se a matéria no seu todo, deviase fazer algum corte em sua realidade, para mais atenda e fecunda consideração (IGLÉSIAS 1959, p. 14).

Não obstante o reconhecimento da necessidade da especialização, Iglésias não ignorou que "não existe, em toda a sua pureza, o fato econômico, o fato político, o fato artístico ou religioso", e que a decomposição do fato social em diferentes aspectos seria necessária para observá-lo melhor, conforme ensinava Marc Bloch, autor insistentemente citado. Ao estudioso seria impossível "manterse com rigor na sua esfera, sem episódicas interferências em campo alheio" (IGLÉSIAS 1959, p. 16-17). Daí que, objetivando pesquisar a política econômica da província mineira para elaboração de sua tese, ele não se viu obrigado a restringir-se à vida econômica. Seu propósito foi "evidenciar a realidade econômica, a situação material sob a influência do governo" (IGLÉSIAS 1959, p. 12), sendo assim, precisava dar atenção ao elemento político e administrativo.

Além de tentar preencher uma lacuna na historiografia com a produção de um conhecimento original, é possível que Francisco Iglésias tenha sido influenciado na escolha de seu tema por uma indicação relativa aos documentos utilizados. O cientista social Manuel Diegues Júnior, ao comentar a publicação, declarou que ele próprio já havia chamado a atenção em sua coluna no jornal Diário de Notícias para as falas e mensagens dos Presidentes de Província como documentos valiosos para a reconstituição da vida provincial e da própria história do Império, fonte notadamente privilegiada pelo autor (DIEGUES JÚNIOR 1959). $\mathrm{O}$ artigo teria sido publicado seis anos antes, exatamente quando Iglésias dava início à sua investigação. Para Diegues Júnior, a maneira como os problemas da administração eram encarados, encaminhados ou resolvidos na vida provincial, revelava grande parte do segredo da história do Império brasileiro. Na sua avaliação, estudos assim deveriam ser seguidos por outros historiadores em relação às demais Províncias, pois "trata-se de contribuição fundamental para que se escreva, no devido tempo, a história do Império, ainda tão vazia" (DIEGUES JÚNIOR 1959).

\section{Os exercícios de crítica e de autocrítica}

Quando terminou a sua tese, Francisco Iglésias escreveu uma longa carta à professora Alice Canabrava expondo os problemas que já percebia em seu trabalho e manifestando desânimo em relação a ele. A partir da resposta da correspondente, pudemos inferir que Iglésias reclamou das "imprecisões", do 
caráter incompleto e do "tom cronista" de seu próprio trabalho. Sua autocrítica denunciava sua insegurança em relação ao cumprimento dos pressupostos que ele mesmo havia postulado. Canabrava, que fez parte da comissão julgadora do concurso, tratou de consolá-lo:

Acredito sinceramente que seu trabalho vale - com todas as imperfeições que você mesmo aponta. Sua tese deve ter muitos aspectos positivos e entre os muitos um é evidente: a sua coragem em se propor em realizar a pesquisa, em meio adverso. Outro: a base sólida, das fontes primárias. São aspectos positivos e que ficam, Iglésias, a despeito de tudo o que puderem criticar, atacar, ou destruir do seu trabalho. ${ }^{6}$

Após a publicação da tese, entretanto, as resenhas e os vários comentários que revelam a repercussão imediata do seu trabalho se ativeram em pormenores. ${ }^{7}$ As notas de Daniel de Carvalho sobre o livro-foram feitas para destacar o que seriam, para o crítico, três problemas da tese: a omissão de duas fábricas de tecido de Itabira na relação das principais da Província; a consideração da escravidão como razão preponderante para afastar as correntes migratórias para o Brasil; e a parte referente aos índios, que pareceu a Carvalho "muito sumária e omissa" (CARVALHO 1959, p. 4). As críticas foram posteriormente incluídas no livro Ensaios de crítica e de história (1964), do mesmo autor, acrescentadas de outras observações sobre a maneira como Francisco Iglésias tratou de temas como a agricultura, a siderurgia, a navegação fluvial, o ensino técnico e as estradas de Minas Gerais em sua tese.

Contra a afirmação de que "ainda que não animada pelo Governo Português que Ihe criou até alguns embaraços - pois só pensava em outra riqueza desenvolveu-se a lavoura de subsistência" (IGLÉSIAS 1958, p. 61), Carvalho argumentou que a metrópole estimulou a agricultura e a criação de animais para o suprimento das minas de ouro. Esse incentivo se dava, sobretudo, através da oferta de sesmarias. Se houve proibição de engenhos em certos períodos, aconteceu em decorrência da política econômica mercantilista e da preocupação de que a abundância de aguardente pudesse comprometer a ordem na colônia, segundo Carvalho. Em relação à indústria, o crítico também questionou as afirmações de que a atividade industrial mineira foi feita "sem assistência técnica ou auxílio dos poderes públicos" e de que a Coroa portuguesa procurava evitar o trabalho industrial (IGLÉSIAS 1959, p. 90-91). Ele lembrou que a siderurgia sempre mereceu apoio da monarquia lusitana e ofereceu dados para comprovar os numerosos atos da metrópole em favor da indústria do ferro. É curioso observar que as críticas de Carvalho às afirmações de Iglésias nestes aspectos se restringem à realidade da Capitania e não da Província, que foi o tema da monografia.

${ }^{6}$ Carta de Alice Canabrava a Francisco Iglésias em 10 de maio de 1954. Instituto Moreira Sales. Coleção Francisco Iglésias.

7 Ver, por exemplo, José (1959), Costa Filho (1959, p. 3), Olinto (1959, p. 12), Degues Júnior (1959), Viana (1959), Campomizzi Filho (1959, p. 4), SODRÉ (1959, p. 6-12), Carvalho (1959a; 1959 b, p. 4, 11), entre outros. 
As minúcias observadas por Carvalho levaram a "correções" de propósito duvidoso. Ao comentar a afirmação de Francisco Iglésias de que as comunicações de Minas Gerais com a Bahia, São Paulo e Rio de Janeiro "foram feitas, um pouco ao acaso, ora aproveitando os caminhos de índios, ora os primeiros trilhos das passadas do sertanista" (IGLÉSIAS 1958, p. 153), ele afirmou que "não se pode emparelhar situações tão díspares", contra-argumentando que a ligação de Minas com Bahia foi sempre pelo Rio São Francisco (CARVALHO 1964 , p. 82). Mas o fato de haver uma linha fluvial de navegação, conforme observou Carvalho, não anulava a constatação de que as picadas orientaram a comunicação terrestre entre aqueles núcleos, conforme enfatizou Iglésias. Outro trecho confrontado por Carvalho foi aquele em que o autor teria afirmado que, "quanto ao índio, por suas condições e traços culturais, não tem grande contribuição nesse particular [a lavoura]" (CARVALHO 1964, p. 70). Entretanto, não encontramos a passagem referida por Carvalho na publicação de 1958 , que foi a sua referência para empreender o comentário à obra.

Entre outros pormenores da tese, "desmentidos por fatos incontestáveis" nas palavras de Carvalho (CARVALHO 1964, p. 79), ele também chamou a atenção para certa ausência de crítica na forma como Francisco Iglésias lidou com a documentação. Em relação ao uso do relatório de 1843, do Presidente Soares Andreia, por exemplo, Carvalho observou que seria preciso considerar o tom pitoresco característico de sua linguagem para perceber os exageros de suas afirmativas (CARVALHO 1964, p. 79). Essa ausência de crítica documental poderia ser encarada como um dos reparos mais graves feito à tese, visto que sua pretensão era justamente utilizar uma documentação copiosa e tratá-la com discernimento e método.

Para Nelson Werneck Sodré, a tese de Francisco Iglésias constituía "contribuição informativa apreciável, útil a todos os que se interessam pelo estudo da nossa história econômica" (SODRÉ 1959, p. 7). Oiliam José destacou que o autor não se deixou levar pelos ciclos então dominantes da economia mineira, abrangendo também as demais atividades produtoras de riqueza na província (JOSÉ 1959, p. 261). Campomizzi Filho acrescentou que o grande mérito do trabalho foi não ter se concentrado no estudo da economia interna de Minas Gerais, mas apresentar o debate do problema administrativo das províncias. 0 que o resenhista mais valorizou foi o que a tese trouxe de informação da história política. Ele elogiou a estruturação dos capítulos e a linguagem agradável, ao mesmo tempo em que afirmou que a tese de Francisco Iglésias "prestou às nossas letras históricas um admirável serviço" (CAMPOMIZZI FILHO 1959, p. 4).

Mas o lugar de onde estes críticos falavam não era aquele no qual Francisco Iglésias havia buscado posicionar o seu trabalho. Embora Campomizzi Filho tenha afirmado que o empenho para que a tese aparecesse em livro foi decorrente da repercussão que ela conseguiu nos meios acadêmicos brasileiros, o fato é que a historiografia produzida pela universidade privilegiaria, pelo menos até meados dos anos 1970, os modelos explicativos da economia colonial como reflexo da dinâmica internacional. As observações sobre a carência de estudos da província mineira feitas na década de 1950 rsitária retomou o assunto no contexto da 
crítica da tese da decadência de Minas Gerais no século XIX. ${ }^{8}$ Os estudos que tiveram como objetivo compreender a colônia a partir de suas condições internas renovaram o interesse pelo conhecimento das realidades regionais e, consequentemente, procuraram estabelecer um diálogo com os exíguos trabalhos sobre o tema realizados no passado. A originalidade da tese de Francisco Iglésias - objetivo perseguido em função de sua concepção de trabalho universitário tornou inevitável o retorno da historiografia contemporânea à sua obra. ${ }^{9}$

\section{Considerações finais}

As primeiras produções do historiador Francisco Iglésias a partir de sua efetivação como docente na UFMG mostram que sua inserção na prática formal do discurso acadêmico refletiu na maneira como ele concebeu a pesquisa cientifica e na forma como ele diferenciou a sua historiografia de outras narrativas históricas alheias ao ambiente universitário. Embora a alteração do lugar privilegiado da produção histórica que ocorreu com a ampliação do ensino superior brasileiro e a institucionalização dos cursos de história não tenha correspondido imediatamente a uma substancial modificação das questões e das metodologias na abordagem do passado, houve uma reconfiguração da função social do historiador e da legitimação de seu trabalho diante daqueles que não possuíam uma formação especializada.

O processo de normatização disciplinar do conhecimento histórico deixou suas marcas nos empreendimentos de escrita específicos através da estruturação do texto, das justificativas teórico-metodológicas, das citações e dos diálogos com outros historiadores. Procuramos estes indícios nos textos de Francisco Iglésias para averiguar tanto as mudanças suscitadas pela dinâmica universitária da produção do conhecimento, como as permanências de ideias e práticas nem sempre coerentes com o discurso que buscava superá-las.

Vimos que a vinculação institucional do texto de Francisco Iglésias foi indiciada pela justificação da escolha temática de sua tese de livre docência, pelo exercício da autolocalização de sua contribuição intelectual, pelo diálogo com a bibliografia pertinente e com outros pesquisadores da comunidade científica que garantiam a linguagem referencial da sua historiografia. Seu discurso historiográfico conduziu o leitor ao próprio lugar de onde falava: ele mostrou que sua escrita era controlada por práticas consideradas inerentes à instituição ao qual estava vinculado - a universidade -, o que supostamente a tornava mais legítima.

\footnotetext{
${ }^{8}$ A tese da decadência de Minas Gerais no século XIX foi defendida por Celso Furtado em 1959. Ela pode ser considerada como herdeira dos estudos de Caio Prado Júnior sobre a economia colonial, interpretada como dependente do mercando internacional e carente de mercado interno. De fato, para ser plenamente compreendida, essa tese deve ser analisada no contexto dos modelos explicativos da economia colonial, pois a hipótese de uma "involução" econômica em Minas Gerais é tributária da perspectiva de que a colônia seria incapaz de promover acúmulo de capital de forma endógena. A crítica da tese da decadência de Minas Gerais apareceu quando se questionou a incapacidade da colônia de reter parte do excedente acumulado.

9 Os trabalhos recentes que recuperaram o diálogo com a tese de Francisco Iglésias foram realizados, sobretudo, por pesquisadores da história econômica, dentre os quais destacamos: Godoy e Barbosa (2008) e Freitas (2009).
} 


\section{Referências bibliográficas}

BOURDIEU, Pierre. Homo academicus. Florianópolis: Ed. UFSC, 2011.

CAMPOMIZZI FILHO. Política econômica do governo provincial mineiro. Folha de Minas, p. 4, 23 abr. 1959.

CARVALHO, Daniel de. Notas ao livro do Prof. Francisco Iglésias: a tecelagem, a imigração, os silvícolas. O Diário, 15 out. 1959.

A economia da província de Minas Gerais. In:

Ensaios de crítica e de história. Rio de Janeiro: edição do autor, 1964.

CERTEAU, Michel de. A escrita da história. 2. ed. Rio de Janeiro: Forense, 2008.

CÔRTES, Norma. Debates historiográficos brasileiros: a querela contra o historicismo. In: MOLLO, Helena Miranda et al. (Org.). A dinâmica do historicismo: revisitando a historiografia moderna. Belo Horizonte: Argvmentvm, 2008, p. 229-243.

DELACROIX, Christian; DOSSE, François; GARCIA, Patrick. Correntes históricas na França: séculos XIX e XX. Rio de Janeiro: FGV, 2012.

DIEGUES JÚNIOR, Manuel. A vida provincial. Diário de Notícias, 5 abr. 1959.

FERREIRA, Marieta de Moraes. A História como ofício: a constituição de um campo disciplinar. Rio de Janeiro: FGV, 2013.

FOUCAULT, Michel. A ordem do discurso. São Paulo: Loyola, 2003.

GRAFTON, Anthony. As origens trágicas da erudição: pequeno tratado sobre a nota de rodapé. Campinas: Papirus, 1998.

HECKSHER, Eli F. La época mercantilista. México: Fondo de Cultura Económica, 1943.

IGLÉSIAS, Francisco. Generalidades sobre a história de Minas Gerais. Estado de Minas, p. 1, 19 jun. 1949.

. Minas e um problema da historiografia brasileira. Tribuna de Minas, 1 mai. 1952.

- Aspectos do desenvolvimento da história econômica. Revista da Faculdade de Ciências Econômicas, n. 6, p. 15-39, 1954.

Política Econômica do Governo Provincial Mineiro (1835-1889). Rio de Janeiro: INL, 1958.

JOSÉ, Oiliam. Historiografia Mineira. Belo Horizonte: Itatiaia, 1959.

SODRÉ, Nelson Werneck. Uma tese. O Semanário, ano IV, n. 162, 6 a 12 jun. 1959.

Monografias. O Semanário, ano IV, n. 171, 8 a 14 ago. 1959. 